\title{
Takt und Taktilität
}

Zwischen geregeltem Rhythmus und individueller Abweichung, zwischen Distanz und Berührung entfaltet sich das Spannungsfeld von Takt und Taktilität, das ästhetische Reflexionen seit der Antike angeregt hat. Dieses Spannungsfeld ist Gegenstand der interdisziplinären Beiträge, die das vorliegende Themenheft versammelt. Verschiedene Konstellationen von Takt und Taktilität werden in Künsten und Medien beleuchtet, die vom Kupferstich über den Buchdruck und die Literatur bis hin zu Tanz und Film reichen. Die Beiträge zeigen, dass sich in der Verbindung der ästhetischen Kategorie des Takts mit dem Taktilen die Sphären von Sinneswahrnehmung, Ästhetik und Gesellschaft überkreuzen. Die Beziehungen zwischen Aisthesis, Ästhetik und Formen des Sozialen, die mit der Koppelung von Takt und Taktilität sichtbar werden, untersuchen die Beiträge in einem historischen Rahmen, der vom 17. Jahrhundert bis in die Gegenwart führt. Spezifische Konturen der jeweils zeitgenössischen Konzepte von Takt und Taktilität zeigen sich dabei ebenso wie Verweise auf frühere oder Antizipationen späterer Konzeptualisierungen.

In ihrem Beitrag „Sinn und Sinnlichkeit der Allegorie: Ikonografien des Tactus um 1600" analysiert Sandra Fluhrer bildallegorische Darstellungen des Tastsinns in der frühen Neuzeit und zeigt, wie das Darstellungsprinzip durch die den Stichen eigene Rhythmizität des Visuellen strukturiert ist. Die taktile Dimension des Mediums Buch arbeitet Michael Auer in seinem Text „Saytenspiel. Die Drucklegung des Taktes 1733-1805“ heraus, der die typografische Realisierung metrischer Muster im 18. Jahrhundert behandelt, die eine neue soziale Praxis der performativen Rezeption von Lyrik begründet. Hanna Sohns faltet in ihrem Beitrag Stéphane Mallarmés Diagnose zur Verskrise in der Moderne, „On a touché au vers“, zu einer literarischen Theorie des Berührens aus, die sich aus den Ambivalenzen der Berührung zwischen Nähe und Distanz, Stiftung und Bruch erzeugt. Aus den Schriften Theodor W. Adornos geht der Takt in seiner Eigenschaft als produktionsästhetische Kategorie hervor, wie Elisa Ronzheimer in ihrem Aufsatz „Der ,Takt der Hand'. Adornos Taktbegriff und die Kritik des Klassizismus“ darlegt, der den Begriff in Adornos ästhetischem Denken kontextualisiert und auf seine Übertragbarkeit auf soziale Zusammenhänge hin befragt. Gabriele Brandstetter zeigt in ihrem Beitrag „In Tact? Synchronisierungen und Berührungen im Tanz“ auf, wie der Takt 
die rhythmische Regulierung mit dem Aus-dem-Takt-Tanzen verbindet. Als räumliche Ordnungskategorie ermöglicht Takt eine tänzerische Berührung auf Distanz. Eine Alternative zur modernistischen Opposition von technizistischem Takt und organizistischem Rhythmus, die sich in der Verbindung von Takt und Taktilität auftut, nimmt schließlich Friederike Felicitas Günther in ihrer Analyse von Ridley Scotts Film A Good Year (2006) in den Blick.

Die Beiträge sind aus Vorträgen für den Workshop Takt und Taktilität hervorgegangen, der am 29. und 3o. November 2018 im Rahmen des DFGNetzwerks Berühren: literarische, mediale und politische Figurationen am Leibniz-Zentrum für Literatur- und Kulturforschung stattfand. Wir danken allen Teilnehmerinnen und Teilnehmern für die angeregten Diskussionen, die die Arbeit an diesem Themenheft geprägt haben.

\author{
Sandra Fluhrer \\ Dr. phil., Komparatistik und Neuere deutsche Literatur, Department \\ Germanistik und Komparatistik, Friedrich-Alexander-Universität \\ Erlangen-Nürnberg, Erlangen, Deutschland \\ sandra.fluhrer@fau.de
}

\author{
Andrea Erwig \\ Dr. phil., Arbeitsbereich Neuere deutsche Literatur, Institut für Deutsche \\ Philologie, Universität Greifswald, Greifswald, Deutschland \\ andrea.erwig@uni-greifswald.de
}

Jakob Gehlen

Dr. phil., Karlsgymnasium München, München, Deutschland gehlen@posteo.de

\title{
Elisa Ronzheimer
}

Dr. phil., Literaturwissenschaft, Universität Bielefeld, Bielefeld, Deutschland elisa.ronzheimer@uni-bielefeld.de 